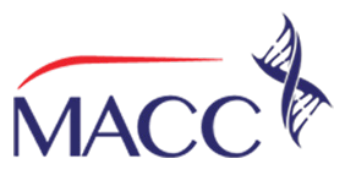

\title{
Analgesia pada Pasien Pediatri
}

\author{
Aida Rosita Tantri \\ Editor in Chief Majalah Anestesia \& Critical Care
}

DOI: 10.55497/majanestcricar.v38i2.202

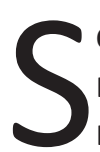
ering sekali kita mendengar anak bukanlah miniatur orang dewasa. Kalimat ini menunjukkan adanya perbedaan yang nyata antara pasien dewasa dan anak. Perkembangan pesat ilmu kedokteran dan kecanggihan alat kedokteran masa kini, tidak dapat menggantikan pentingnya pemahaman yang khusus dalam tatalaksana anestesi pasien pediatri. Anak-anak, terutama bayi yang baru berusia beberapa bulan, sangat berbeda dari orang dewasa. Perbedaan anatomi, fisiologi, dan psikologi antara dewasa dan anak-anak perlu dipahami dengan baik agar dapat memberikan pelayanan medis yang baik terutama untuk pasien pediatri. ${ }^{1}$

Tantangan dalam menangani pasien pediatri bukan hanya dalam memberikan tatalaksana yang baik, tetapi juga dalam hal memahami apa yang sebenarnya dialami oleh anak tersebut. Anak-anak yang belum bisa berkomunikasi dengan baik membuat dokter terkadang hanya bisa menebak yang dirasakan dan dialami oleh pasien. ${ }^{2}$ Interpretasi rasa nyeri yang dialami anak merupakan tantangan untuk seorang tenaga medis. Mitos yang menyatakan bahwa bayi dan anak tidak merasakan nyeri atau merasakan nyeri yang mebih ringan dibandingkan pasien dewasa. Pemahaman ini membuat deteksi dan penanganan nyeri pada pasien pediatri menjadi tidak adekuat. ${ }^{1,3}$

American Academy of Pediatric dan American Pain Society merekomendasikan agar rasa nyeri pada pasien pediatri segera dikenali dan ditangani dengan agresif. ${ }^{4} \mathrm{Hal}$ ini penting karena penanganan nyeri yang efektif dan adekuat dapat meminimalisir respons stres akut dan sensitasi sistem saraf pusat yang dapat menyebabkan peningkatan persepsi nyeri, dan gangguan tingkah laku di kemudian hari. ${ }^{1,4,5}$ European Society for Paediatric Anaesthesiology (ESPA) dalam ESPA Pain Management Ladder Initiative tahun 2018 juga mempublikasikan pedoman tatalaksana nyeri intrabedah dan pascabedah untuk pasien pediatri yang menjalani berbagai jenis operasi. Tujuan dikeluarkannya pedoman ini adalah untuk meningkatkan kualitas tatalaksana nyeri pasien pediatri terutama pada periode pascabedah. ${ }^{5}$

Setidaknya $80 \%$ populasi global terkena dampak akibat penanganan nyeri yang tidak adekuat dan menyebabkan masalah serius di lebih dari 150 negara. $^{5}$ Sebuah penelitian epidemiologi yang dilakukan oleh Carbajal et al. tahun 2008 menyatakan bahwa bayi yang dirawat di Neonatal Intensive Care Unit (NICU) rata-rata menjalani 75 tindakan yang menimbulkan rasa nyeri selama dirawat di NICU dengan rerata 10 tindakan per hari, dimana 79,2\% tindakan dilakukan tanpa menggunakan analgetik. ${ }^{6}$ Cruz et al. pada artikel review miliknya di tahun 2015 menyebutkan bahwa tindakan tersering di NICU yang menghasilkan rasa nyeri adalah heel lance, suctioning, venepuncture, dan pemasangan jalur vena perifer. Dari total 18 studi yang diikutsertakan dalam review, dua studi melaporkan bahwah 100\% tindakan yang dilakukan di NICU tidak menggunakan analgetik jenis apapun dan tiga studi lainnya melaporkan tingginya jumlah tindakan dan jumlah subjek 
yang tidak diberikan analgetik selama perawatan di NICU (70-95\%). ${ }^{7}$ Review ini membuktikan bahwa masih banyak kesalahan pemahaman konsep nyeri pada pasien pediatri.

Faktanya, sistem saraf sudah berkembang sempurna dari sebelum bayi lahir, demikian pula dengan saraf nosiseptif. Karenanya, pasien pediatri dapat merasakan nyeri dari saat dilahirkan. ${ }^{4}$ Pain assessment scale pada bayi dan anak-anak yang belum dapat berkomunikasi sudah banyak divalidasi oleh banyak penelitian, namun validasi sistem penilaian nyeri tersebut dilakukan secara observasional dan penilaian subjektif peneliti. Cara terbaik untuk mengetahui rasa nyeri adalah metode pelaporan mandiri (self-report) yang baru mulai dapat dilakukan pada anak di atas usia 18 bulan. ${ }^{3,4}$

Tatalaksana nyeri pada pediatrik memerlukan kerjasama tim dari berbagai disiplin ilmu untuk melakukan asesmen rutin dan mendiskusikan program tatalaksana nyeri yang terbaik untuk pasien. ${ }^{2,3}$ Tatalaksana nyeri dapat berupa tatalaksana farmakologi dan non-farmakologi. Tatalaksana farmakologi berupa obat-obatan dari berbagai golongan dengan kekuatan analgetik yang berbeda-beda. Tatalaksana non-farmakologi terdiri dari strategi fisiologis dan psikologis. Strategi fisiologis yang dapat dilakukan misalnya dengan melakukan teknik pijat, kompres, perubahan posisi dan lainnya. Strategi psikologis biasanya berupa cognitive behavioral therapy untuk menghadapi stresor dan mengurangi kecemasan pasien. 3,4,8

Agen analgetik yang ideal memiliki beberapa karakterisktik, yaitu memiliki onset yang cepat, efek analgesia mudah terprediksi, mudah diberikan dan tidak nyeri saat pemberian, murah, dan tidak memiliki efek samping. ${ }^{9}$ Cara yang dapat diandalkan untuk mengontrol nyeri adalah pemberian analgetik melalui jalur intravena. Pemberian analgetik melalui jalur intravena dapat dititrasi dan dikontrol sesuai kebutuhan sehingga dapat memaksimalkan pengendalian nyeri, menambah dosis sesuai kebutuhan, dan meminimalisir terjadinya efek toksik dari obat. Pemberian obat secara peroral, rektal, dan intramuskular memiliki keuntungan dan kerugiannya masing-masing sehingga perlu dipertimbangkan penggunaannya secara seksama. ${ }^{4.9}$ Penanganan nyeri dengan teknik lainnya seperti blok perifer atau patient controlled analgesia (PCA) juga dapat dilakukan sesuai keilmuan dan pertimbangan dari masingmasing tenaga medis. ${ }^{3}$

Agen analgetik dapat diberikan kepada pasien pediatri sesuai kebutuhan. Nyeri ringan dapat ditatalaksana dengan pemberian parasetamol atau obat golongan Obat Anti-inflamasi Nonsteroid (OAINS). Nyeri sedang-berat dapat ditangani dengan pemberian obat analgetik secara multimodal dengan tambahan analgetik kuat seperti ketamin, opioid, dan obat golongan lainnya. ${ }^{4,9}$ Metamizol adalah analgetik lama yang dapat digunakan pada pasien pediatrik. Metamizol $15 \mathrm{mg} / \mathrm{kgBB}$ memiliki efektifitas serupa dengan asetaminofen $15 \mathrm{mg} / \mathrm{kgBB}$ intravena untuk analgesia pascabedah bawah umbilikus pada pasien pediatrik. ${ }^{10}$

\section{DAFTAR PUSTAKA}

1. Gehdoo RP. Post operative pain management Davis PJ, Cladis FP. Smith's Anesthesia for Infants and Children. 9th ed. St. Louis, Missouri: Elsevier; 2017.

2. Wright JA. An update of systemic analgesics in children. Anaesth Intensive Care Med [Internet].2019;20(6):324-9. Available from: https://doi.org/10.1016/ j.mpaic.2019.03. 010

3. Gai N, Naser B, Hanley J, Peliowski A, Hayes J, Aoyama K. A practical guide to acute pain management in children. J Anesth. 2020;34(3):421 - 33 .

4. Objectives E. Module 6 Pain Management: Pediatric Pain Management Module 6 Pain Management: Pediatric Pain Management American Academy of Orthopaedic Surgeons. Children. 2012;7:1 - 12.

5. Vittinghoff M, Lönnqvist PA, Mossetti V, Heschl $S$, Simic D, Colovic V, et al. Postoperative pain management in children: Guidance from the pain committee of the European Society for Paediatric Anaesthesiology (ESPA Pain Management Ladder Initiative). Paediatr 
Anaesth. 2018;28(6):493 - 506.

6. Carbajal R, Rousset A, Danan C, et al. Epidemiology and treatment of painful procedures in neonates in intensive care units. JAMA. 2008; 300(1):60 - 70.

7. Cruz MD, Fernandes $A M$, Oliveira $C R$. Epidemiology of painful procedures performed in neonates: A systematic review of observational studies. Eur J Pain (United Kingdom). 2016;20(4):489-98.

8. Chae F. Integrated Approach to Pediatric Chronic Pain Management [Internet]. 2017 [Disitasi pada tanggal 23 Juli 2020]. Available from: https://www.asra.com/asra-news/ article/82/integrated-approach-to-pediatricchronic.

9. O'Donnell JJ, Maurice SC, Beattie TF. Emergency analgesia in the paediatric population. Part III non-pharmacological measures of pain relief and anxiolysis. Emerg Med J. 2002;19(3):195 - 7.

10. Ramlan A. A. W., Sukmono R. B., Banadji Y. M. Perbandingan Efektivitas Metamizol 15 $\mathrm{Mg} / \mathrm{KgBB} \mathrm{IV}$ dengan Asetaminofen $15 \mathrm{Mg} /$ KgBB IV untuk Analgesia Pasca-Bedah di Bawah Umbilikus pada Pasien Pediatrik. MajAnestCriCar. 2020; 38(2): $99-110$. 